\title{
Bidirectional regulation of dopamine D2 and neurotensin NTS1 receptors in dopamine neurons
}

\author{
C. Jomphe, ${ }^{1}$ P.-L. Lemelin, ${ }^{1}$ H. Okano, ${ }^{2}$ K. Kobayashi ${ }^{3}$ and L.-E. Trudeau ${ }^{1}$ \\ ${ }^{1}$ Department of Pharmacology, Faculty of Medicine, Groupe de Recherche sur le Système Nerveux Central, Centre de Recherche \\ Fernand Seguin, Université de Montréal, Montréal, Québec, Canada \\ ${ }^{2}$ Department of Physiology, Kieo University School of Medicine, Japan \\ ${ }^{3}$ Department of Molecular Genetics, Fukushima Medical University, Japan
}

Keywords: culture, GPCR, mice, patch-clamp, receptor interaction

\begin{abstract}
Several lines of evidence suggest a close association between dopamine (DA) and neurotensin (NT) systems in the CNS. Indeed, in the rodent brain, abundant NT-containing fibres are found in DA-rich areas such as the ventral tegmental area and substantia nigra. Moreover, it has been shown in vivo that NT, acting through its high-affinity receptor (NTS1), reduces the physiological and behavioural effects of DA D2 receptor (D2R) activation, a critical autoreceptor feedback system regulating DA neurotransmission. However, the mechanism of this interaction is still elusive. The aim of our study was thus to reproduce in vitro the interaction between D2R and NTS1, and then to characterize the mechanisms implicated. We used a primary culture model of DA neurons prepared from transgenic mice expressing green fluorescent protein under the control of the tyrosine hydroxylase promoter. In these cultures, DA neurons endogenously express both D2R and NTS1. Using electrophysiological recordings, we show that activation of D2R directly inhibits the firing rate of DA neurons. In addition, we find that NT, acting through a NTS1-like receptor, is able to reduce D2R autoreceptor function independently of its ability to enhance DA neuron firing, and that this interaction occurs through a protein kinase C- and $\mathrm{Ca}^{2+}$-dependent mechanism. Furthermore, prior activation of D2R reduces the ability of NTS1 to induce intracellular $\mathrm{Ca}^{2+}$ mobilization. Our findings provide evidence for bidirectional interaction between D2R and NTS1 in DA neurons, a regulatory mechanism that could play a key role in the control of the activity of these neurons.
\end{abstract}

\section{Introduction}

Neurotensin (NT) is an endogenous tridecapeptide that is widely distributed throughout the mammalian CNS (Fassio et al., 2000). In the rodent brain, a high density of NT-immunoreactive fibres innervates dopamine (DA)-rich areas such as the ventral tegmental area (VTA) and substantia nigra (SN) (Uhl et al., 1977; Jennes et al., 1982; Quirion, 1983; Binder et al., 2001; Zahm et al., 2001). Furthermore, NT receptors, predominantly the type 1 high-affinity receptor (NTS1), are expressed in SN and VTA DA neurons (Palacios \& Kuhar, 1981; Uhl, 1982; Quirion et al., 1985; Moyse et al., 1987; Brouard et al., 1992; Nicot et al., 1995; Fassio et al., 2000). NT acting on NTS1 receptors has an excitatory effect on midbrain DA neurons (Pinnock, 1985; Seutin et al., 1989; Mercuri et al., 1993; Jiang et al., 1994; Farkas et al., 1996). In addition to this excitatory effect, a number of indirect evidence suggests that NT also acts to regulate DA neurons indirectly by modulating the function of the DA D2 receptor (D2R) (Binder et al., 2001).

At the cellular level, NTS1 and D2R are present within some of the same axon terminals and dendrites (Delle Donne et al., 2004). In addition, NT produces a modest decrease in the affinity of the D2R for its agonists (von Euler et al., 1989; Fuxe et al., 1992; Tanganelli et al., 1993; Li et al., 1995). However, the nature and mechanism of the

Correspondence: Dr L.-E. Trudeau, as above.

E-mail: louis-eric.trudeau@umontreal.ca

Received 17 July 2006, revised 25 August 2006, accepted 30 August 2006 antagonistic interaction between NTS1 and D2R has not yet been elucidated. Several hypotheses have been proposed. A first hypothesis is that NTS1 and D2R oppositely regulate a similar potassium conductance in DA neurons (Farkas et al., 1997); NT would thus simply prevent D2 agonists from activating the potassium channels by independently inhibiting them. Another plausible hypothesis is that activation of NTS1 leads to second messenger-dependent D2R alterations such as phosphorylation. Accordingly, it has been shown in heterologous cell lines that protein kinase $\mathrm{C}$ (PKC) can phosphorylate D2R, resulting in functional desensitization (Rogue et al., 1990; Namkung \& Sibley, 2004). Because NTS1 activates the phospholipase C (PLC)/inositol phosphate (IP) 3 /PKC pathway (Hermans \& Maloteaux, 1998; Vincent et al., 1999), it is thus possible that the functional regulation of D2R exerted by NT results from a heterologous desensitization phenomenon.

In the present study we used primary cultures of mesencephalic neurons from tyrosine hydroxylase (TH)-enhanced green fluorescent protein (EGFP) transgenic mice (Jomphe et al., 2005) to investigate the mechanisms underlying the interaction between D2R and NTS1. In this model, DA neurons can be identified by the expression of enhanced green fluorescent protein (EGFP), and they endogenously express both D2R and NTS1. Using electrophysiological recordings, we evaluated the ability of NT to modulate D2R-mediated inhibition of firing rate. We found that NT, through activation of a NTS1-like receptor, is indeed able to reduce D2 autoreceptor function, and that this interaction occurs through a PKC- and $\mathrm{Ca}^{2+}$-dependent inhibition 
of D2R function. In addition, prior activation of D2R similarly reduces the ability of NTS1 to induce intracellular $\mathrm{Ca}^{2+}$ mobilization. These results indicate a bidirectional interaction between D2R and NTS1 functions that is involved in the regulation of DA neuron activity.

\section{Materials and methods}

\section{Transgenic mice and cell culture}

The transgenic mice (TH-GFP/21-31 line) carrying the EGFP gene under the control of the TH promoter were described in recent studies (Sawamoto et al., 2001; Matsushita et al., 2002). Transgenic lines were maintained as heterozygotes by breeding with C57BL/6J inbred mice, and offsprings that carried the transgene were identified by polymerase chain reaction (PCR) on the genomic DNA extracted from tail biopsies. A 475-bp fragment of EGFP DNA was amplified by PCR, using the primers: AAGTTCATCTGCACCACCG and TGCTCAGGTATGGTTGTCG. Primary cultures of postnatal mesencephalic neurons were prepared from postnatal day zero TH-GFP/ 21-31 transgenic mice as recently described (Jomphe et al., 2005), according to procedures, including anaesthesia, that were approved by the animal ethics committee of the Université de Montréal. Briefly, neonatal (P0) woose pups were cryoanaesthetized and their brains were rapidly removed and transferred into ice-cold dissociation solution before enzymatic digestion with papain and mechanical trituration. Cells were then plated on astrocyte monolayers and maintained in Neobasal A/B27 medium supplemented with penicillin/streptomycin, GlutaMAX-1 and 10\% fetal calf serum (Gibco, Logan, UT, USA).

\section{Electrophysiology}

Electrophysiological recordings were performed at room temperature on EGFP-expressing living neurons maintained for 10-18 days in culture. Cultures were transferred to a recording chamber that was fixed to the stage of an inverted Nikon Eclipse TE-200 microscope. The coverslip was constantly perfused with physiological saline solution using a gravity flow system $(2.5-3 \mathrm{~mL} / \mathrm{min})$ with a standard extracellular bathing solution containing (in $\mathrm{mM}$ ): $\mathrm{NaCl}, 140 ; \mathrm{KCl}, 5$; $\mathrm{MgCl}_{2}, 2 ; \mathrm{CaCl}_{2}, 2$; HEPES, 10; sucrose, 6; glucose, 10; $\mathrm{pH} 7.35$, $\sim 300 \mathrm{mOsm}$. Drugs were bath applied, with a delay between valve opening and onset of drug action of approximately $15 \mathrm{~s}$. Whole-cell or perforated patch-clamp (using the antibiotic amphotericin B, $150-200 \mu \mathrm{g} / \mathrm{mL}$ ) current-clamp recordings were performed using a Warner PC-505 patch-clamp amplifier (Warner Instruments, Hamden, CT, USA). Signals were filtered at $1 \mathrm{kHz}$, digitized at $10 \mathrm{kHz}$, and recorded and analysed using Pclamp7 software (Axon Instruments, Foster City, CA, USA) and Mini Analysis software (version 5.6) (Synaptosoft, Leonia, NJ, USA), respectively. Action potentials were recorded with borosilicate glass patch pipettes (5-7 M $\Omega$ ) filled with a potassium methylsulphate intrapipette solution containing (in $\mathrm{mM}$ ): $\mathrm{KMeSO}_{4}, 145 ; \mathrm{KCl}, 20$; NaCl, 10; EGTA, 0.1; ATP (Mg salt), 2; GTP (Tris salt), 0.6; HEPES, 10; phosphocreatine (Tris salt), 10 $(\mathrm{pH} 7.35)$ or, when required, a BAPTA intrapipette solution containing (in $\mathrm{mM}$ ): $\mathrm{KMeSO}_{4}, 100 ; \mathrm{KCl}, 20 ; \mathrm{NaCl}, 5$; EGTA, 0.1; ATP (Mg salt), 2; GTP (Tris salt), 0.5; HEPES, 10; phosphocreatine (Tris salt), 10; BAPTA (tetraacetic acid tetrapotassium salt), 10 $(\mathrm{pH} 7.35)$. In all experiments, the firing frequency was normalized to the average frequency recorded during the baseline period $(2 \mathrm{~min}$ before drug application) and expressed as a percentage. The effect of a drug on firing rate was determined as the ratio of mean firing frequency at the peak of the effect (usually $1 \mathrm{~min}$ for the effect of the
D2 agonist quinpirole) to the average frequency measured during baseline and washout periods. This calculation method takes into account any rundown in firing rate that could occur during long recording periods. Post hoc immunocytochemistry against TH was performed systematically to confirm dopaminergic phenotype. The proportion of EGFP-expressing neurons that expressed TH was approximately $80 \%$. Neurons not expressing TH were excluded from further analysis.

\section{Calcium imaging}

Changes in cytosolic intracellular $\mathrm{Ca}^{2+}$ concentrations $\left(\left[\mathrm{Ca}^{2+}\right]_{\mathrm{i}}\right)$ were measured with fura-2. Briefly, cells grown on 15-mm coverslips were loaded with fura- 2 by incubating in saline (pH 7.4) containing $5 \mu \mathrm{M}$ fura-2-AM and $0.02 \%$ pluronic acid (Molecular Probes, Eugene, OR, USA) for $45 \mathrm{~min}$ at room temperature. For $\left[\mathrm{Ca}^{2+}\right]_{\mathrm{i}}$ measurements, the coverslip was mounted in a recording chamber that was fixed to the stage of an inverted Nikon Eclipse TE-200 microscope. The coverslip was constantly perfused with physiological saline solution (containing in mM: $\mathrm{NaCl}, 140 ; \mathrm{KCl}, 5 ; \mathrm{MgCl}_{2}, 2 ; \mathrm{CaCl}_{2}, 2$; HEPES, 10; glucose, 10; sucrose, 6; at a $\mathrm{pH}$ of 7.35) added with $5 \mu \mathrm{M}$ tetrodotoxin (Alomone Laboratories, Jerusalem, Israël) to prevent $\mathrm{Ca}^{2+}$ variations due to action potentials. $\left[\mathrm{Ca}^{2+}\right]_{\mathrm{i}}$ was measured by digital fluorescence imaging using Ratiotool software (Inovision Corporation, Raleigh, NC, USA). Fluorescence excitation at $340 / 380 \mathrm{~nm}$ was controlled by a DG4 xenon lamp (Sutter Instruments, Novato, CA, USA). Fluorescence was collected after passing through a 495-nm long-pass filter. Excitation image pairs $(340 / 380 \mathrm{~nm})$ were acquired every $5 \mathrm{~s}$ with an Orca-II digital cooled-CCD camera (Hamamatsu, Bridgewater, NJ, USA). $\left[\mathrm{Ca}^{2+}\right]_{\mathrm{i}}$ was calculated using an in situ calibration protocol and Grynkiewicz's equation (Grynkiewicz et al., 1985). In experiments evaluating the effect of $\mathrm{NT}(8-13)$ on $\left[\mathrm{Ca}^{2+}\right]_{\mathrm{i}}$, neurons were considered responsive if they showed an increase in $\left[\mathrm{Ca}^{2+}\right]_{\mathrm{i}}$ of more than twice the standard deviation of $\left[\mathrm{Ca}^{2+}\right]_{\mathrm{i}}$ measured during the baseline period. The amplitude of the effect of NT was calculated as the difference between the maximal $\left[\mathrm{Ca}^{2+}\right]_{\mathrm{i}}$ increase at the peak (obtained 2 min after the beginning of the application of NT) and the $\left[\mathrm{Ca}^{2+}\right]_{i}$ measured during a 1-min baseline period prior to the application. Two responses to NT were successively measured in the same cell, separated by an interval of $20 \mathrm{~min}$. Drug effects were determined by comparing the amplitude of the initial NT-evoked $\left[\mathrm{Ca}^{2+}\right]_{\mathrm{i}}$ elevation to that of the second response measured in the presence of different drugs (SR48692, quinpirole).

\section{Immunocytochemistry}

Cells were fixed with $4 \%$ paraformaldehyde in phosphate-buffered saline ( $\mathrm{pH}$ 7.4) and incubated with a monoclonal anti-TH antibody (TH-2 clone) (Sigma-Aldrich, Oakville, Ontario, Canada) to confirm DA phenotype. The primary antibody was visualized using an Alexa546-labelled secondary antibody (Molecular Probes). Coverslips were mounted with Vectashield (Vector Laboratories, Burlingame, CA, USA) and observed by epifluorescence microscopy on a Nikon Eclipse TE-200 inverted microscope.

\section{Statistical analysis}

The results are expressed as arithmetic means \pm SEM, with each observation $(n)$ corresponding to a single recording made on neurons from different coverslips. For statistical analysis, two-factor ANOVA and $t$-tests were used as indicated. 


\section{Results \\ Quinpirole-induced inhibition of DA neuron firing rate is dose dependent and does not desensitize}

In a previous study, we showed that cultured DA neurons prepared from TH-EGFP mice possess the well-known physiological and pharmacological properties of DA neurons (Jomphe et al., 2005). Indeed, these neurons possess functional D2 autoreceptors and show an inhibition of their firing rate in response to a D2 agonist. Using electrophysiological recordings, we first characterized the inhibition of firing rate induced by quinpirole, a D2R-selective agonist. Whole-cell perforated patch-clamp recordings were obtained from EGFP-expressing DA neurons, identified by epifluorescence prior to recording. As expected, quinpirole ( 0.1 and $1 \mu \mathrm{M})$ reduced the spontaneous firing rate in a dose-dependent manner (Fig. 1A, B and D), with the highest concentration producing a significant effect. Activation of D2R with $1 \mu \mathrm{M}$ quinpirole induced a $59.7 \pm 14.1 \%$ reduction in firing frequency $(n=6$, Student's $t$-test for paired observations, $P=0.03$ ), while this inhibition was limited to $20.1 \pm 6.9 \%$ with $0.1 \mu \mathrm{M}(n=6$, Student's $t$-test for paired observations, $P=0.1$ ). In addition, we confirmed that the effect of quinpirole $(1 \mu \mathrm{M})$ on firing rate was the result of D2 autoreceptor activation as sulpiride $(5 \mu \mathrm{M})$, a D2R antagonist, totally prevented this effect $(n=4$, Student's $t$-test for paired observations, $P=0.93)$. Therefore all subsequent experiments were performed with $1 \mu \mathrm{M}$ quinpirole (Fig. 1D).

Because subsequent experiments involved repeated applications of quinpirole, we next verified whether two successive applications of the D2 agonist caused a reproducible response. We found that when spaced by a 6-min interval, two applications of quinpirole $(1 \mu \mathrm{M}$, for $2 \mathrm{~min}$ ) induced a similar inhibition of the firing rate of cultured DA neurons $(\mathrm{Q} 1=59.7 \pm 14.1 \%, \mathrm{Q} 2=56.1 \pm 12.1 \% ; n=6$, Student's $t$-test for paired observations, $P=0.8$ ) (Fig. $1 \mathrm{C}$ and $\mathrm{E}$ ). This suggests that the response mediated by D2 autoreceptor activation does not show acute desensitization.

\section{Activation of NT receptor reduces D2 autoreceptor function}

We next aimed to reproduce in vitro the interaction previously seen in vivo between the $\mathrm{D} 2 \mathrm{R}$ and NT receptors. We assessed the ability of the active fragment of NT [NT(8-13)] to modulate the effect of the D2 agonist quinpirole on the firing rate of cultured DA neurons. During each recording, we first evaluated the effect of quinpirole alone (Q1, $1 \mu \mathrm{M})$, and then a second application of quinpirole was done in the presence of NT(8-13) (1 nM). It should be noted that NT(8-13) by itself often caused an increase in firing rate, followed, in some cells, by brief periods of inactivity. Only neurons displaying stable firing in the presence of NT(8-13) were considered for further analysis. NT(8-13) was applied for $10 \mathrm{~min}$ starting $3 \mathrm{~min}$ before the second application of quinpirole (Q2). We found that the effect of the second application of quinpirole, in the presence of $\mathrm{NT}(8-13)$, was significantly reduced relative to the first one (Fig. 2A and C). In the presence of NT(8-13), the inhibition of firing rate induced by quinpirole was limited to $35.0 \pm 5.1 \%$, in comparison to $78.9 \pm 7.9 \%$ when applied alone ( $n=5$, Student's $t$-test for paired observations, $P=0.008$ ).

We next used SR48692 (1 $\mu \mathrm{M})$ and SR142948A (100 nM), a selective NTS1 and a mixed NTS1/NTS2 receptor antagonist, respectively, to evaluate the implication of these receptors in the modulatory effect of NT(8-13) on D2 autoreceptor function. Each antagonist was present during the complete duration of these experiments. Our results show that SR48692 as well as SR142948A blocked the modulatory effect of NT(8-13) on D2R function (Fig. 2B and $\mathrm{D}$ ), while they did not affect the ability of the D2R agonist to reduce the firing rate of DA neurons. Indeed, in the presence of
SR48692, the first application of quinpirole induced a decrease of $72.0 \pm 6.0 \%$ in the firing rate, while the second application performed in the presence of $\mathrm{NT}(8-13)$ produced a decrease of $58.3 \pm 10.1 \%$. The two responses were not statistically different $(n=7$, Student's $t$ test for paired observations, $P=0.08$ ). Similarly, the first application of quinpirole produced an inhibition of firing rate of $64.3 \pm 6.7 \%$ in the presence of SR142948A, while the second application of quinpirole performed in the presence of NT(8-13) reduced firing by $54.8 \pm 6.5 \% \quad(n=6$, Student's $t$-test for paired observations, $P=0.18$ ). Because the mixed NTS1/NTS2 antagonist did not block the modulatory effect of $\mathrm{NT}(8-13)$ to a greater extent than the selective NTS1 antagonist and because NTS1 is expressed at a high level in DA neurons, we conclude that the effect of NT(8-13) on D2R function is mainly mediated through the high-affinity NTS1 receptor.

\section{Modulation of D2R function by NT is independent of its ability to increase the firing rate of $D A$ neurons}

The excitatory effect of NT on DA neurons is well established (Palacios \& Kuhar, 1981; Pinnock, 1985; Seutin et al., 1989; St-Gelais et al., 2004; Jomphe et al., 2005). One possibility is that the interaction between D2R and NTS1 is simply the consequence of their opposite effect on DA neurons excitability. However, this explanation is unlikely as the excitatory effect of NT(8-13) was variable and the receptor interaction could be detected even in experiments where the excitatory effect of NT(8-13) was modest (Fig. 2A). Nonetheless, we tested this possibility by evaluating the ability of NT to inhibit D2R function under conditions where we interfered with the excitatory effect of the peptide. In cultured DA neurons from rat midbrain, we have previously shown that blocking $\mathrm{IP}_{3}$ receptors using heparin prevented the excitatory effect of NT (St-Gelais et al., 2004). We first reproduced this finding by showing that inclusion of heparin $(1 \mathrm{mg} / \mathrm{mL})$ in the intrapipette solution blocks the excitatory effect of NT(8-13) (Fig. 3A, B and D). Indeed, in the presence of heparin, NT(8-13) increased the firing rate by only $37.6 \pm 16.4 \%$ over baseline, compared with $293.9 \pm 105.5 \%$ when applied alone ( $n=7$, Student's $t$-test, $P=0.04$ ). However, under such conditions, NT was still able to negatively regulate D2 autoreceptor function: when DA neurons were exposed to $\mathrm{NT}(8-13)$ in the presence of heparin, the inhibition of firing rate induced by quinpirole was still smaller $(41.3 \pm 10.5 \%)$ in comparison to the first application of quinpirole in the absence of $\mathrm{NT}(8-13)(69.9 \pm 5.1 \%) \quad(n=9$, Student's $t$-test for paired observations, $P=0.03$; Fig. $3 \mathrm{C}$ and $\mathrm{E}$ ). Therefore, we can conclude that the excitatory effect of NT is not necessary for the interaction seen in vitro between D2R and NTS1.

\section{The functional interaction between D2R and NTS1 requires calcium}

NTS1 is functionally coupled to the PLC IP signalling cascade (Hermans \& Maloteaux, 1998; Vincent et al., 1999), leading to $\mathrm{Ca}^{2+}$ elevation in DA neurons, mostly through extracellular $\mathrm{Ca}^{2+}$ influx, with a minor contribution of the $\mathrm{IP}_{3}$ pathway (Borges et al., 1996; StGelais et al., 2004; Jomphe et al., 2005). Although $\mathrm{IP}_{3}$-dependent intracellular $\mathrm{Ca}^{2+}$ store mobilization is not apparently required for the D2R-NTS1 interaction (Fig. 3), a role for $\mathrm{Ca}^{2+}$ influx remains possible. To verify this hypothesis, we recorded cultured DA neurons using an intrapipette solution containing the $\mathrm{Ca}^{2+}$ chelator BAPTA $(10 \mathrm{mM})$. In the presence of BAPTA, the two successive applications of quinpirole, in the absence or presence of NT, produced a similar inhibition of firing rate (BAPTA + Quinpirole: $72.2 \pm 9.1 \%$; BAPTA + Quinpirole + NT: $73.8 \pm 10.6 \%, n=6$, Student's $t$-test for 
A

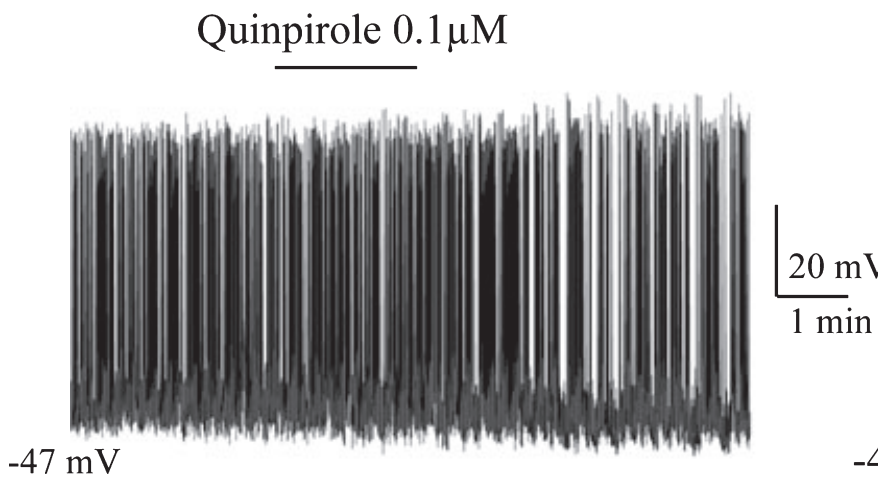

B

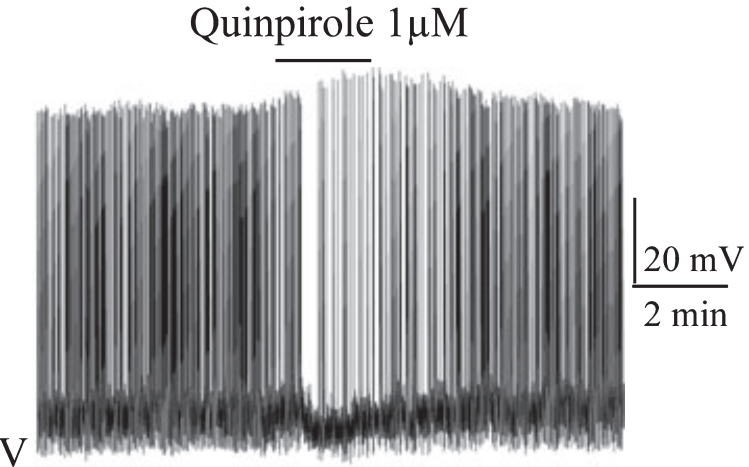

C

Quinpirole $1 \mu \mathrm{M}$

Quinpirole $1 \mu \mathrm{M}$

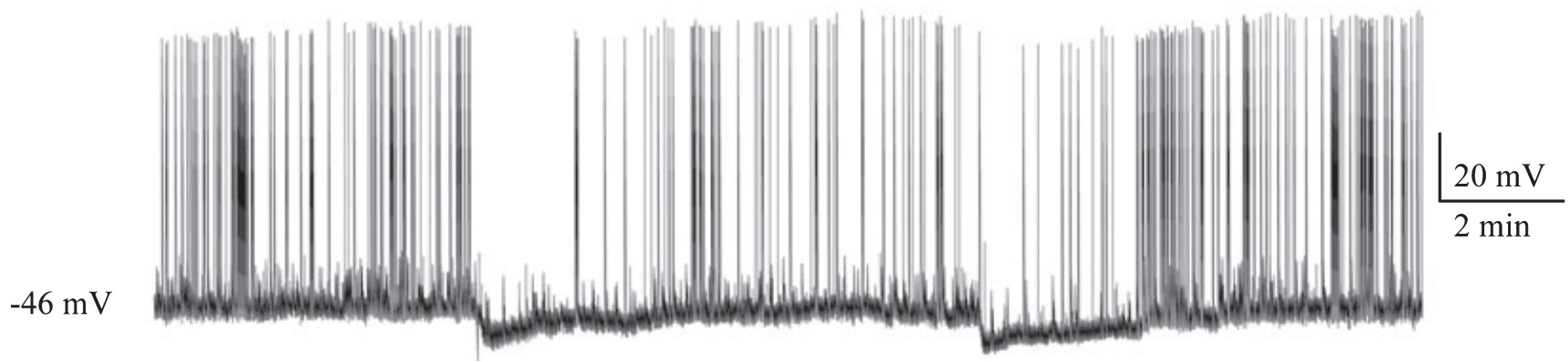

D

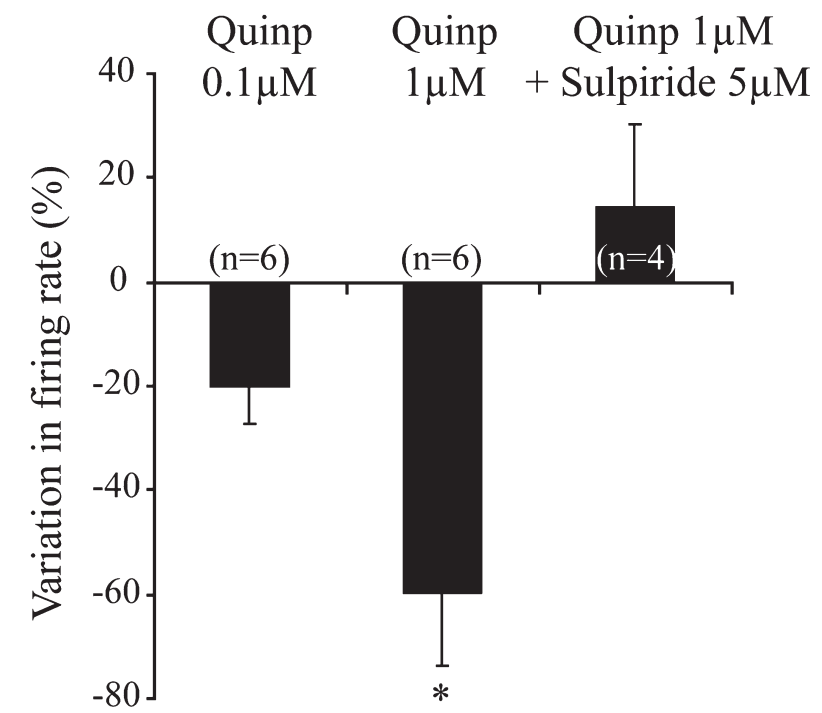

E

Quinpirole $1 \mu \mathrm{M}$ Quinpirole $1 \mu \mathrm{M}$

(Q1)

(Q2)

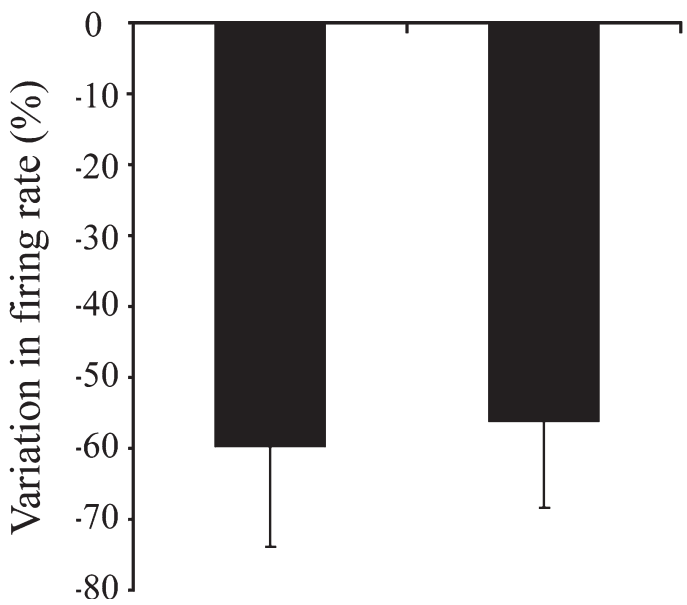

FIG. 1. Effect of quinpirole on the spontaneous firing of DA neurons. (A, B) Representative examples of patch-clamp recordings of spontaneous action potentials in cultured midbrain DA neurons from TH-GFP mice. The D2R agonist quinpirole induced a dose-dependent inhibition of the firing rate. Quinpirole was applied for $2 \mathrm{~min}$ at $0.1 \mu \mathrm{M}(\mathrm{A})$ or $1 \mu \mathrm{M}(\mathrm{B})$. At the highest dose, quinpirole caused a strong reduction in firing rate. (C) Representative recording of spontaneous action potentials in a DA neuron exposed to two successive applications of quinpirole $(1 \mu \mathrm{M}$ for $2 \mathrm{~min})$. (D) Summary graph of the effect of quinpirole (1 $\mu \mathrm{M})$ on the firing rate of DA neurons. Quinpirole produced a significant inhibition of the firing rate that was totally blocked by the selective D2 antagonist sulpiride (5 $\mu \mathrm{M})$. (E) Summary graph showing the mean inhibition of firing rate induced by two successive applications of quinpirole (Q1 and Q2) $(n=6)$. The second application produced an inhibition similar to the first one. Data are expressed as mean \pm SEM. $* P<0.05$. 
A

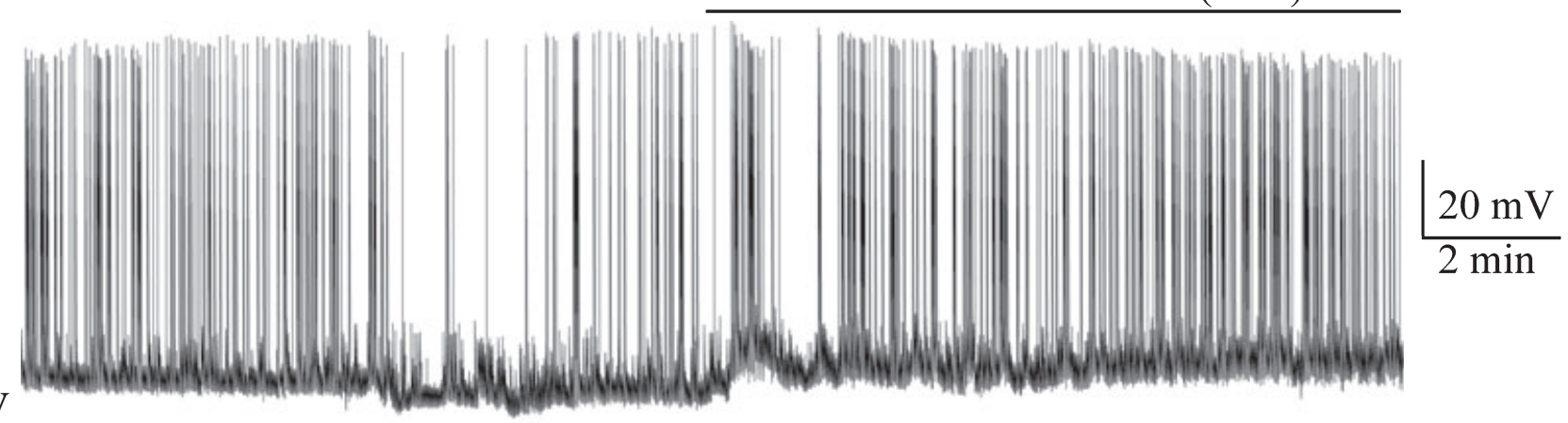

B

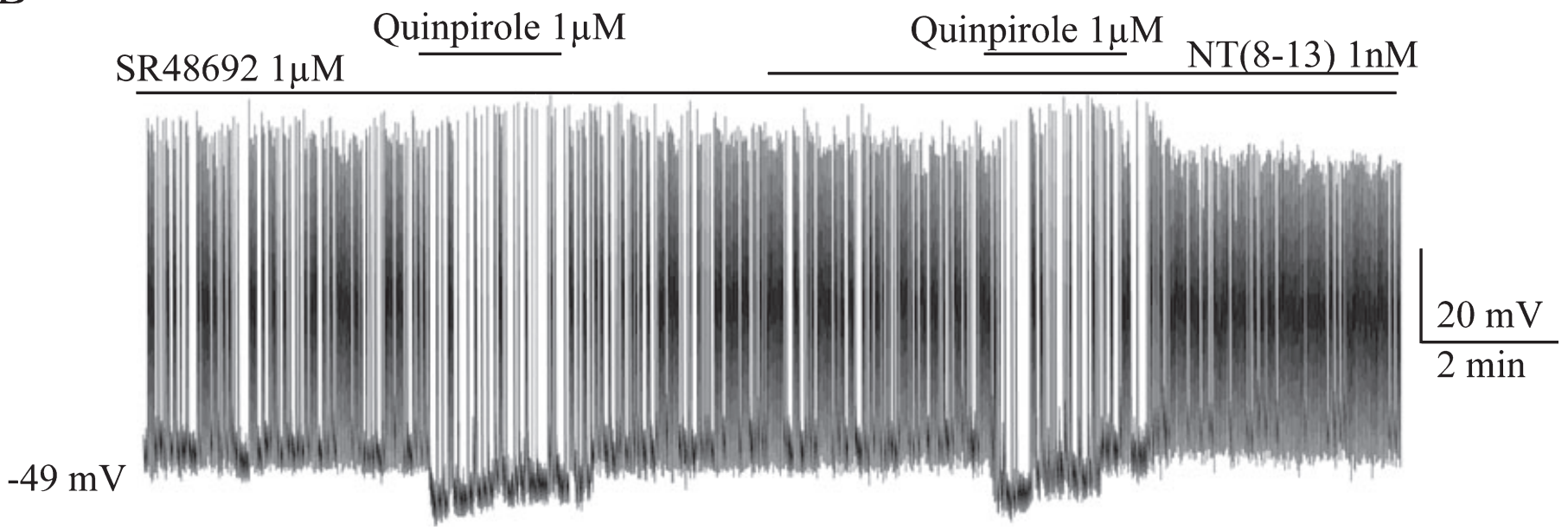

C

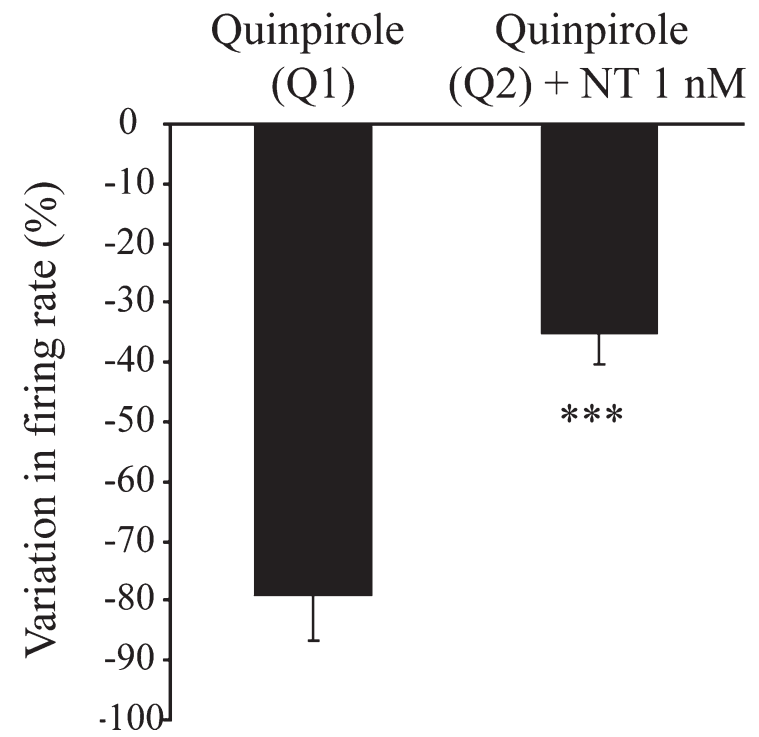

D

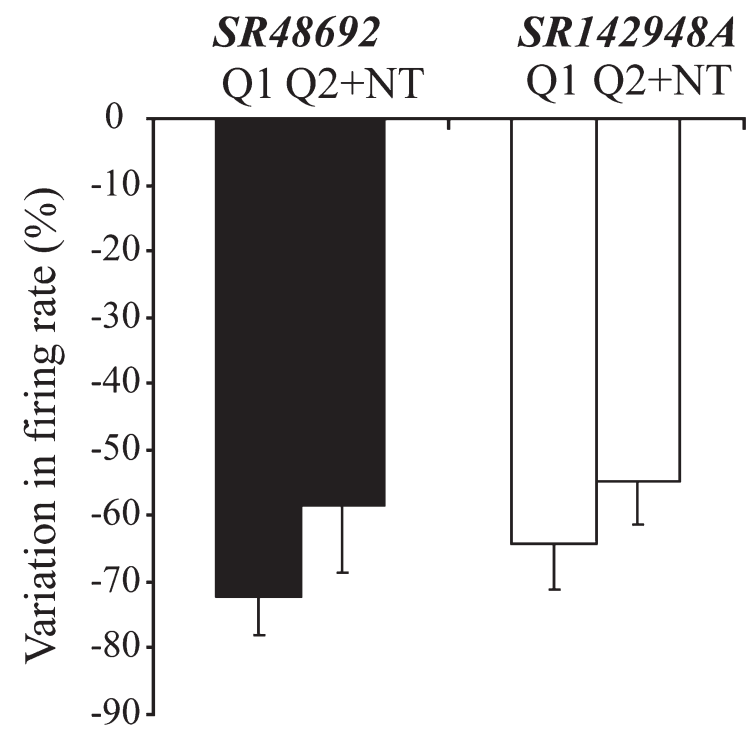

FIG. 2. Activation of NTS1 reduces the effect of quinpirole on firing rate. (A, B) Representative examples of spontaneous action potentials recorded from cultured DA neurons. The second application of quinpirole was made in the presence of $1 \mathrm{nM}$ neurotensin (NT(8-13)) alone (A) or together with the selective NTS1 antagonist SR48692 (1 $\mu \mathrm{M})(\mathrm{B})$. (C) Graph summarizing the effect of NT(8-13) on the quinpirole-induced inhibition of firing rate $(n=5)$. (D) Summary graph of the effect of the selective NTS1 antagonist SR48692 $(1 \mu \mathrm{M})(n=7)$ and the NTS1/NTS2 mixed antagonist SR142948A (100 nM) $(n=6)$ on the ability of $\mathrm{NT}(8-13)$ to inhibit the second response to quinpirole. Data are expressed as mean $\pm \mathrm{SEM}$. ${ }^{* * *} P<0.001$. 
A NT(8-13) $1 \mathrm{nM}$

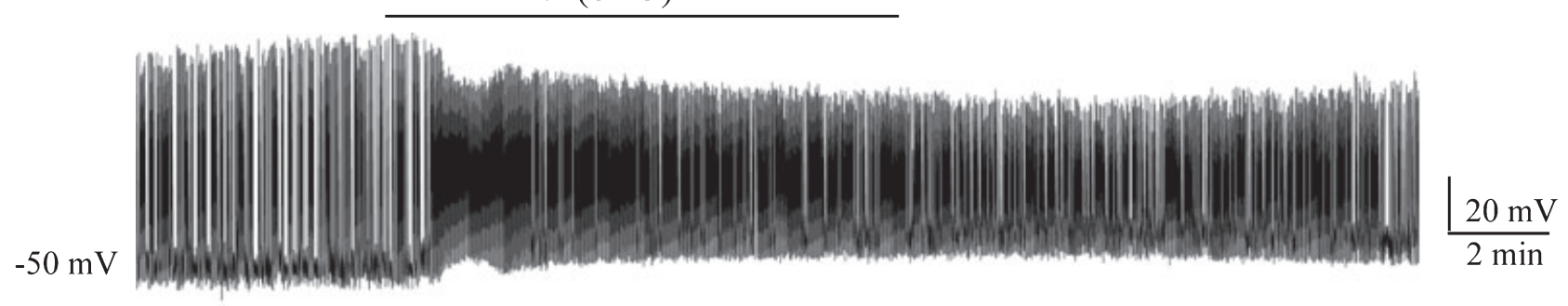

B

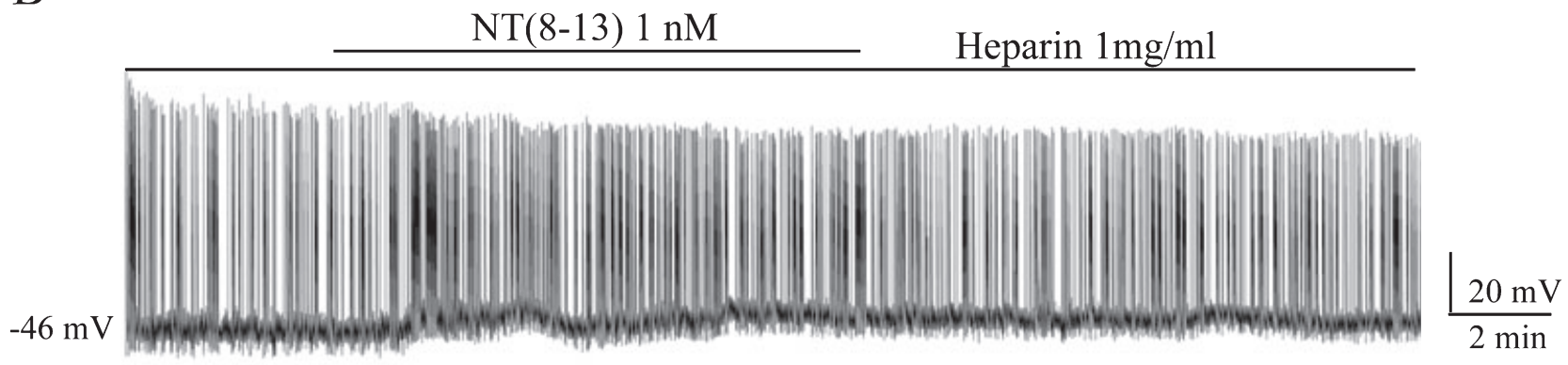

C
Quinpirole $1 \mu \mathrm{M}$

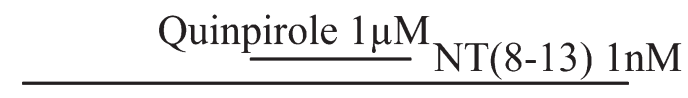 Heparin $1 \mathrm{mg} / \mathrm{ml}$
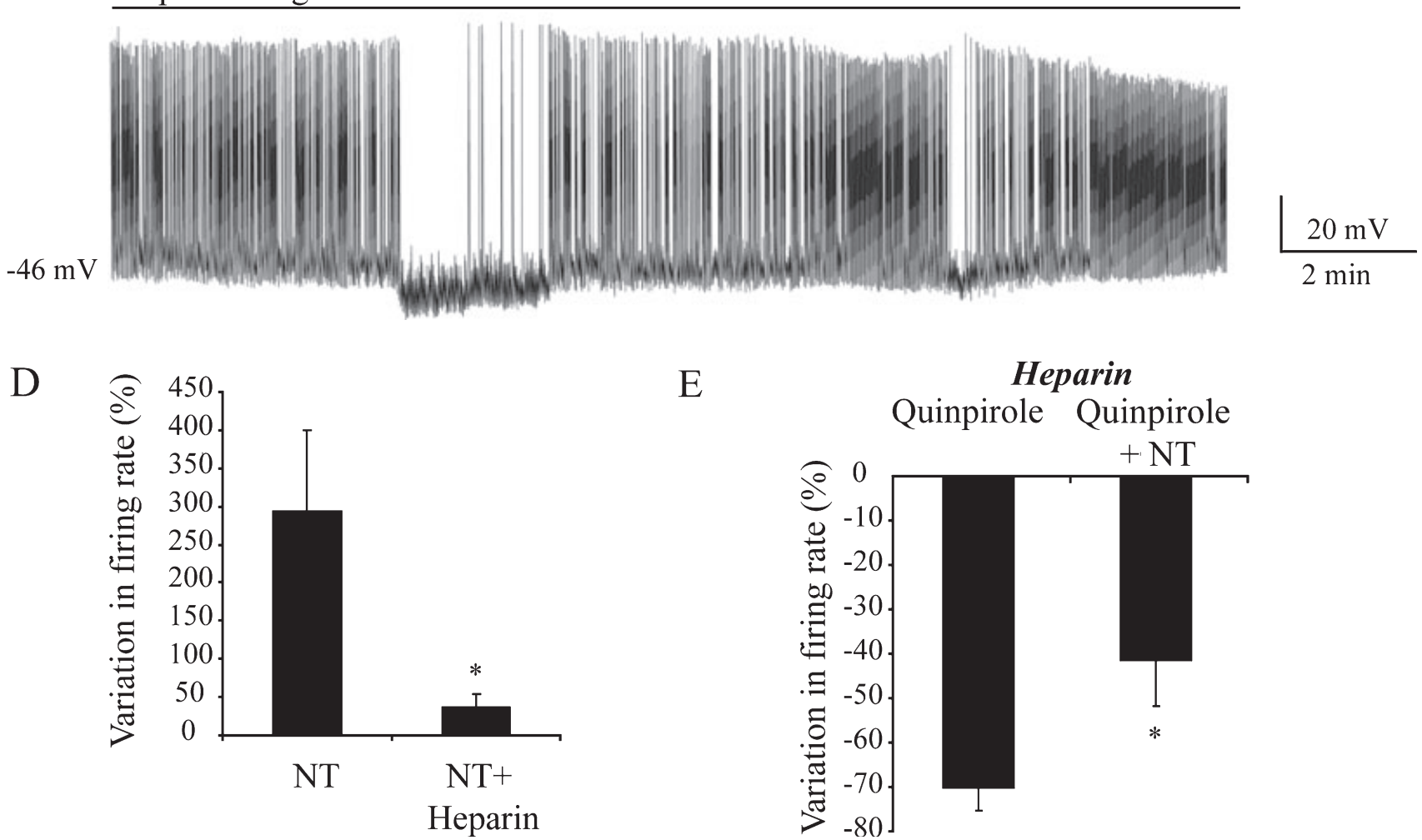

E

Heparin Quinpirole Quinpirole

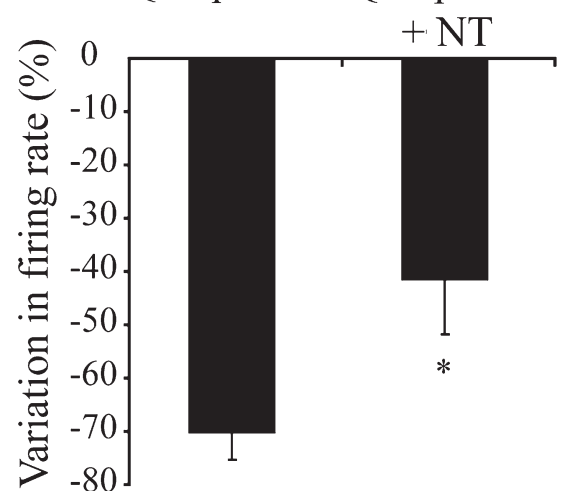

FIG. 3. The excitatory effect of NTS1 is not required for the functional regulation of D2R function. (A, B) Representative recording of the effect of neurotensin $(\mathrm{NT}(8-13))(1 \mathrm{nM}$, for $10 \mathrm{~min})$ on DA neurons. NT(8-13) produced a strong increase in the firing rate of DA neurons (B), an effect that was blocked by heparin $(1 \mathrm{mg} / \mathrm{mL})(B)$. (C) Example of a patch-clamp recording experiment measuring spontaneous action potentials in DA neurons exposed to two successive applications of quinpirole, the second of which was performed in the presence of NT(8-13). The $\mathrm{IP}_{3}$ receptor antagonist heparin $(1 \mathrm{mg} / \mathrm{mL})$, included in the patch pipette, failed to prevent the ability of NT(8-13) to inhibit the effect of quinpirole. (D) Graph summarizing the effect of heparin on NT(8-13)-induced increase in firing $(n=7)$ in comparison to the effect of $\mathrm{NT}(8-13)$ alone $(n=8)$. Note that heparin blocked the excitatory effect of NT(8-13). (E) Summary graph showing the effect of NT(8-13) on quinpirole-evoked inhibition of firing, in the presence of heparin $(n=9)$. Note that heparin failed to prevent the interaction. Data are expressed as mean \pm SEM. $* P<0.05$. 


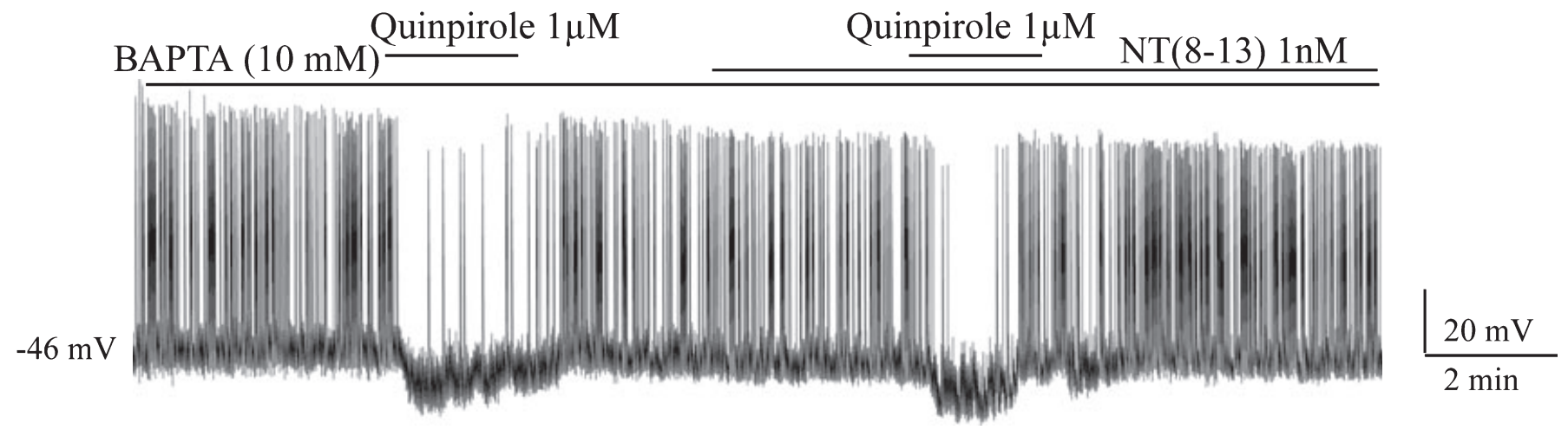

B
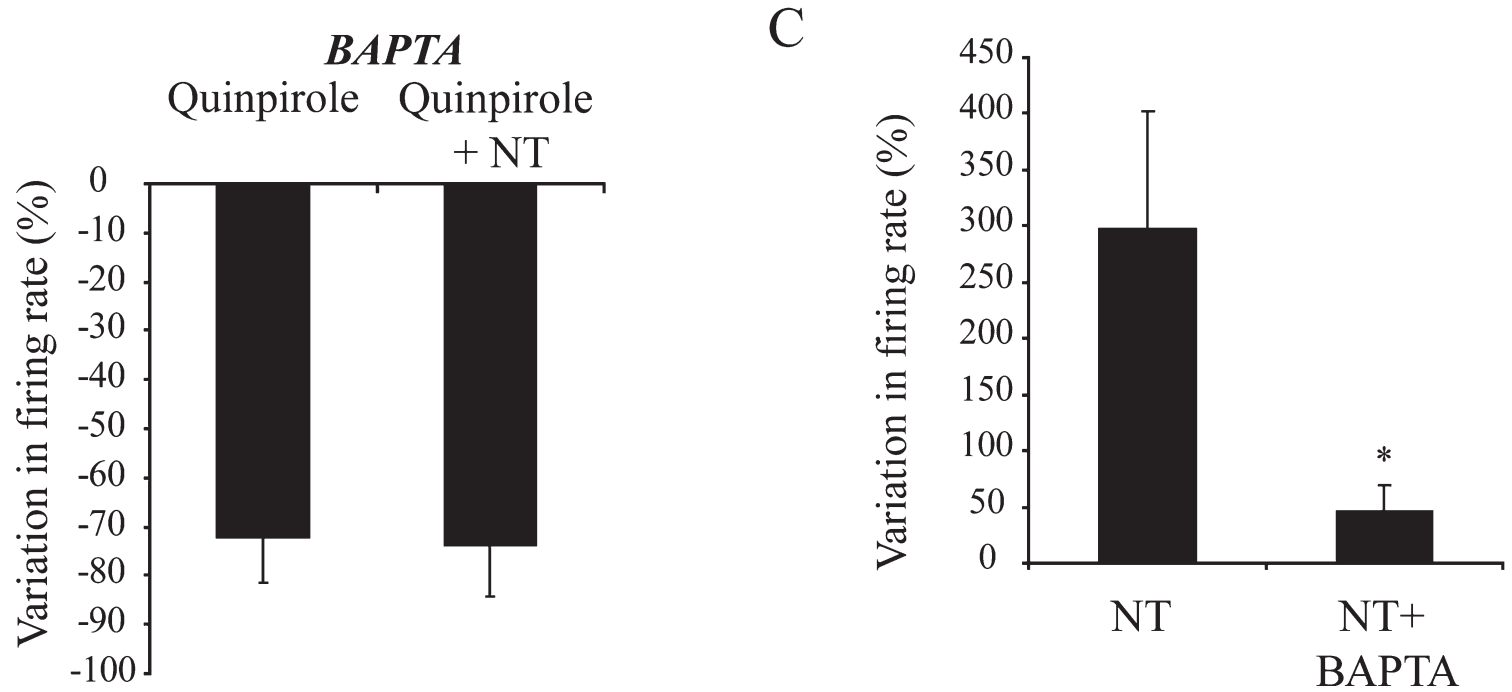

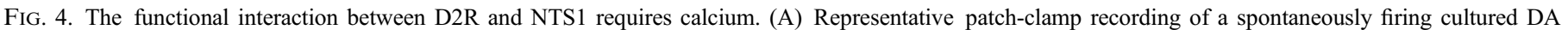

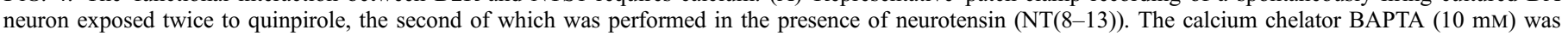

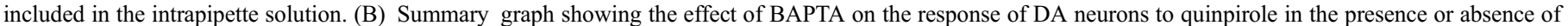

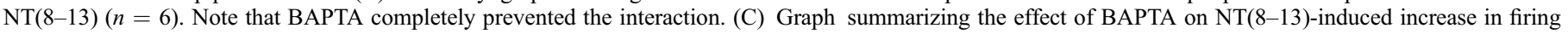

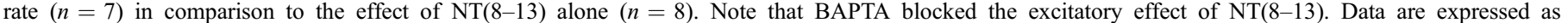
mean \pm SEM. ${ }^{*} P<0.05$.

paired observations, $P=0.80$; Fig. 4 A and $\mathrm{B}$ ), showing that BAPTA totally abolished the functional regulation of D2R seen after NTS1 activation. In addition to blocking this receptor interaction, intrapipette BAPTA, like the $\mathrm{IP}_{3}$ receptors antagonist heparin, blocked the increase in firing rate induced by NT (Fig. 4C). The increase in firing rate was $45.9 \pm 24.2 \%$ in BAPTA-loaded neurons, while it was $297.6 \pm 105.2 \%$ under normal recording conditions $(\mathrm{NT}, n=8$; NT + BAPTA, $n=7$; Student's $t$-test, $P=0.047$ ). We can thus conclude that although the increase in intracellular $\mathrm{Ca}^{2+}$ following NTS1 activation is required both for the increase in the firing rate and for the functional interaction between D2R and NTS1, the two phenomena are apparently not directly linked.

\section{PKC is involved in the functional regulation of D2R by NTS1}

It has been shown, in heterologous expression systems, that D2R signalling is reduced by PKC (Rogue et al., 1990; Namkung \& Sibley, 2004). Because stimulation of NTS1 leads to PLC and PKC activation (Hermans \& Maloteaux, 1998; Vincent et al., 1999), we assessed the implication of this kinase in the interaction between D2R and NTS1 by including PKC(19-36), a selective PKC peptide inhibitor, in the patch pipette. We observed that in the presence of $\mathrm{PKC}(19-36)$ $(10 \mu \mathrm{M})$, the ability of NT(8-13) to reduce the effect of quinpirole on firing frequency was blocked (Fig. 5). The first application of quinpirole produced a $65.2 \pm 8.6 \%$ decrease in the spontaneous firing, while the second application, made after NTS1 receptor activation, caused an inhibition of $52.7 \pm 4.5 \%$, which was not statistically different from the first response $(n=7$, Student's $t$-test for paired observations, $P=0.24$; Fig. $5 \mathrm{~B}$ ). Blocking $\mathrm{PKC}$ activity is thus sufficient to counteract the functional regulation of the D2R by NTS1.

\section{Activation of $D 2 R$ reduces the ability of NT to increase intracellular calcium in DA neurons}

If NTS1 and D2R functionally interact, this interaction could perhaps be bidirectional, with D2R also regulating NTS1 function. To answer this question we performed intracellular $\mathrm{Ca}^{2+}$ imaging experiments, taking advantage of the fact that activation of NTS1 produces an 


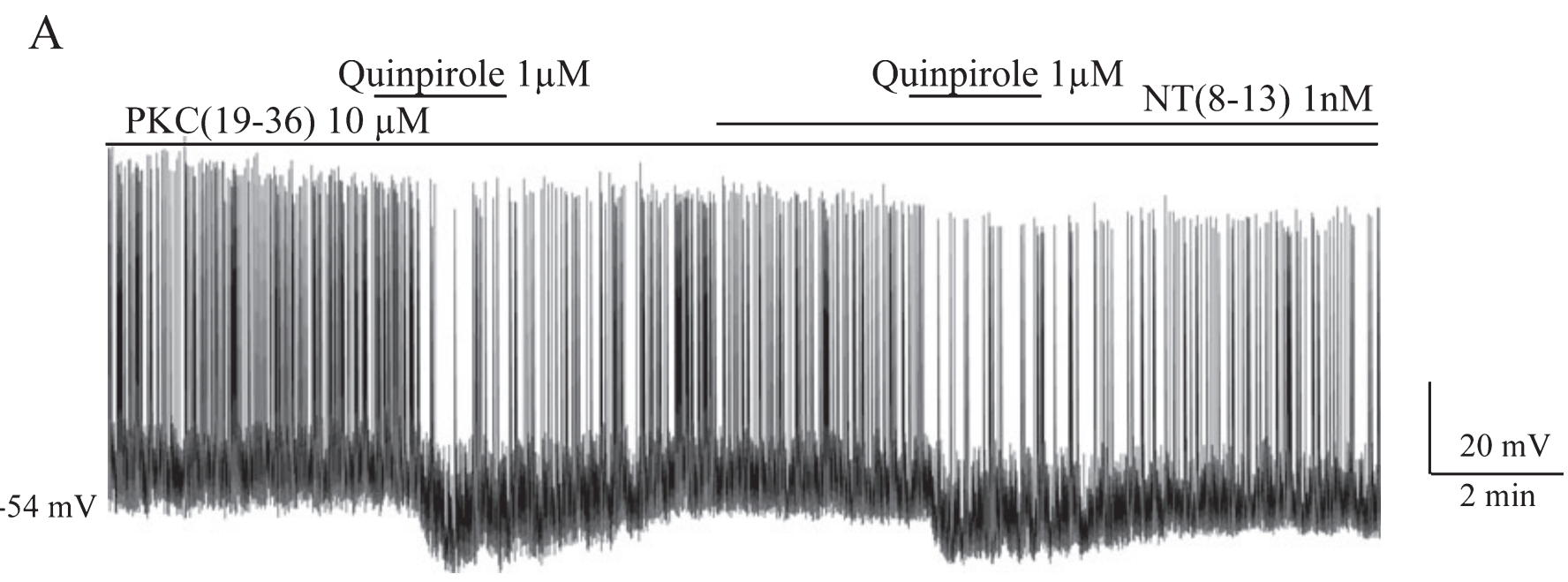

$\mathrm{B}$

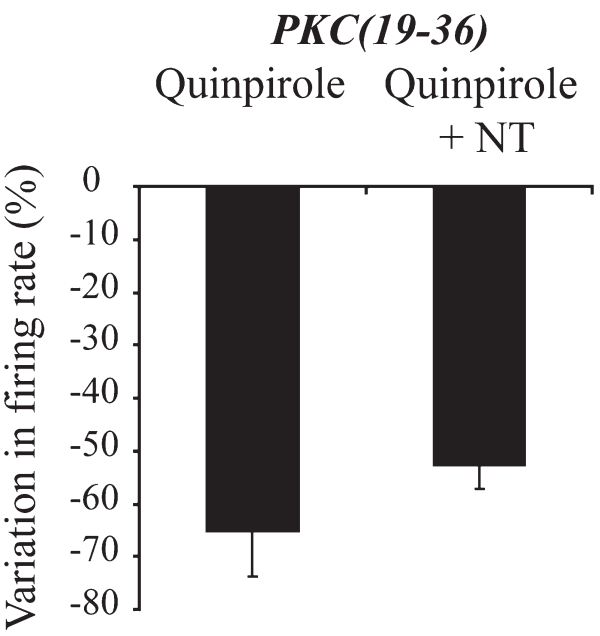

FIG. 5. The functional interaction between D2R and NTS1 is protein kinase C (PKC)-dependent. (A) Representative patch-clamp recording experiment where PKC(19-36) $(10 \mu \mathrm{M})$, a PKC inhibitor, was included in the patch pipette. The recorded DA neuron was first exposed to quinpirole alone and then quinpirole in the presence of neurotensin (NT(8-13)). (B) Summary graph showing that PKC(19-36) prevented the ability of NT(8-13) to negatively regulate the response to quinpirole $(n=7)$. Data are expressed as mean \pm SEM.

increase in $\left[\mathrm{Ca}^{2+}\right]_{\mathrm{i}}$ in both rat and mouse DA neurons (St-Gelais et al., 2004; Jomphe et al., 2005). Cultured neurons were loaded with fura-2$\mathrm{AM}$, a fluorescent $\mathrm{Ca}^{2+}$ indicator, and changes in $\left[\mathrm{Ca}^{2+}\right]_{\mathrm{i}}$ were measured with fura-2 ratio fluorescence in EGFP-expressing DA neurons, identified by epifluorescence prior to the experiment. As expected, application of $\mathrm{NT}(8-13)(10 \mathrm{nM}$, for $2 \mathrm{~min})$ produced a large increase in $\left[\mathrm{Ca}^{2+}\right]_{\mathrm{i}}$ (Fig. 6A), an effect that showed only limited desensitization (Fig. 6B). The first application of NT(8-13) caused an average increase of $794.2 \pm 95.6 \mathrm{nM}$, over the baseline level, while the second application, done $20 \mathrm{~min}$ after the first, led to an average increase of $664.0 \pm 74.0 \mathrm{nM}(n=17$, Student's $t$-test for paired observations, $P=0.01$ ). Calculated on a cell by cell basis, the second response to NT was on average $10.6 \pm 5.5 \%$ smaller than the first (Fig. 6D). The first application of NT also did not lead to any longlasting change in baseline levels of $\left[\mathrm{Ca}^{2+}\right]_{\mathrm{i}}$, as the first baseline value was on average $152.6 \pm 18.4 \mathrm{~nm}$ and the second baseline value, measured just before the second application of NT, was $152.2 \pm 16.5 \mathrm{nM}(n=17$, Student's $t$-test for paired observations, $P=0.97$, results not shown). To evaluate the contribution of NTS1, the sensitivity of this $\mathrm{Ca}^{2+}$ mobilization response to SR48692 was evaluated. We found that SR48692 totally abolished NT(8-13)- induced $\mathrm{Ca}^{2+}$ elevation in DA neurons (not shown). In the presence of SR48692, the increase in $\left[\mathrm{Ca}^{2+}\right]_{\mathrm{i}}$ induced by NT(8-13) was limited to $14.4 \pm 9.8 \mathrm{nM}$, compared with $644.8 \pm 89.0 \mathrm{nM}$ when NT(8-13) was applied alone $(n=8$, Student's $t$-test for paired observations, $P<0.001$ ), corresponding to a $97.2 \pm 1.7 \%$ inhibition.

Finally, to verify if D2R functionally regulates NTS1 signalling, we stimulated D2R with quinpirole $(1 \mu \mathrm{M}) 2 \mathrm{~min}$ prior to the second NT(8-13) application. In the absence of quinpirole, activation of NTS1 receptors leads to a large increase in $\left[\mathrm{Ca}^{2+}\right]_{\mathrm{i}}$ $(940.7 \pm 111.7 \mathrm{nM})$. In response to quinpirole, a small decrease in basal $\left[\mathrm{Ca}^{2+}\right]_{\mathrm{i}}$ was first noted (from $201.1 \pm 22.2 \mathrm{nM}$ to $89.2 \pm 6.6 \mathrm{nM}$ in the presence of quinpirole) $(n=18$, Student's $t$-test for paired observations, $P<0.001$; Fig. $6 \mathrm{C}$ ). In the presence of quinpirole, the second response to $\mathrm{NT}(8-13)$ was on average $623.6 \pm 91.7 \mathrm{nM}(n=8)$, which, calculated on a cell by cell basis, corresponds to a decrease of $37.3 \pm 7.2 \%$ (Student's $t$-test for paired observations, $P<0.001$; Fig. $6 \mathrm{C}$ ), a value that was much higher than the $10.6 \%$ decrement noted in control experiments. Based on these observations, we conclude that the D2R negatively regulates NTS1 function. The interaction seen in vitro between D2R and NTS1 is thus bidirectional. 
A
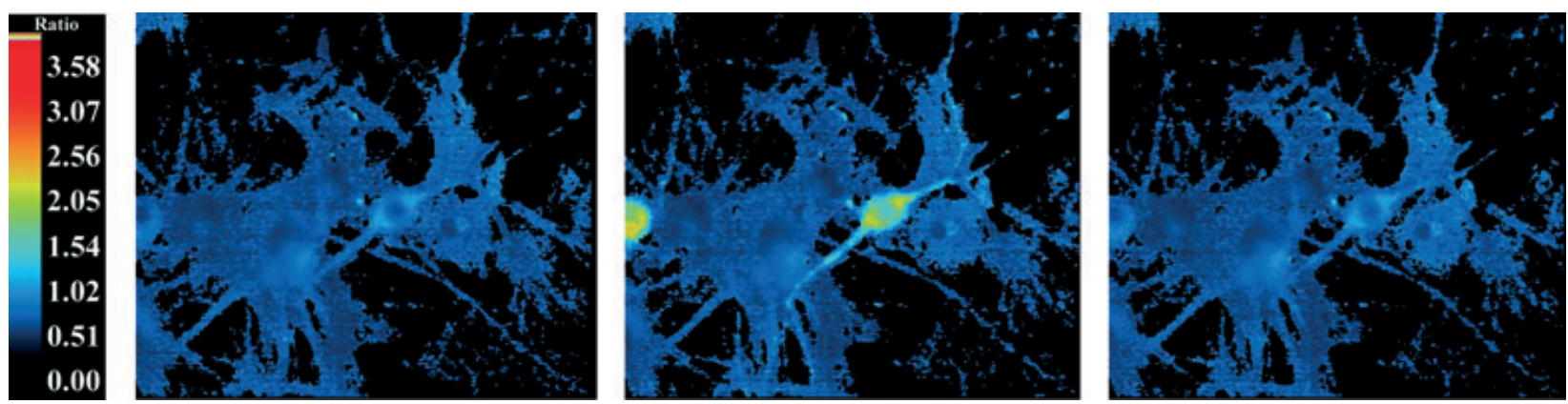

B

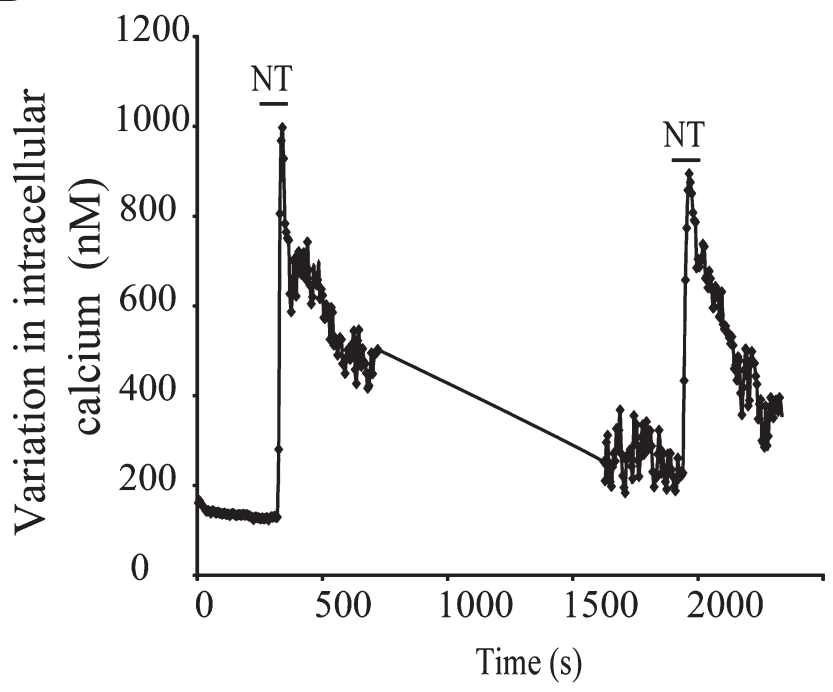

$\mathrm{D}$
C

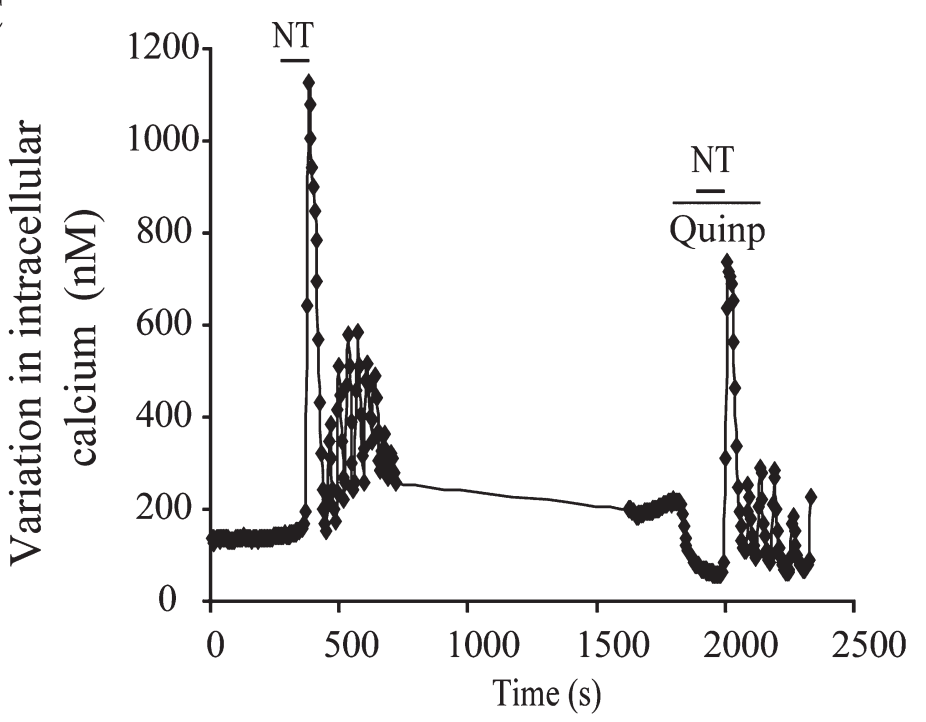

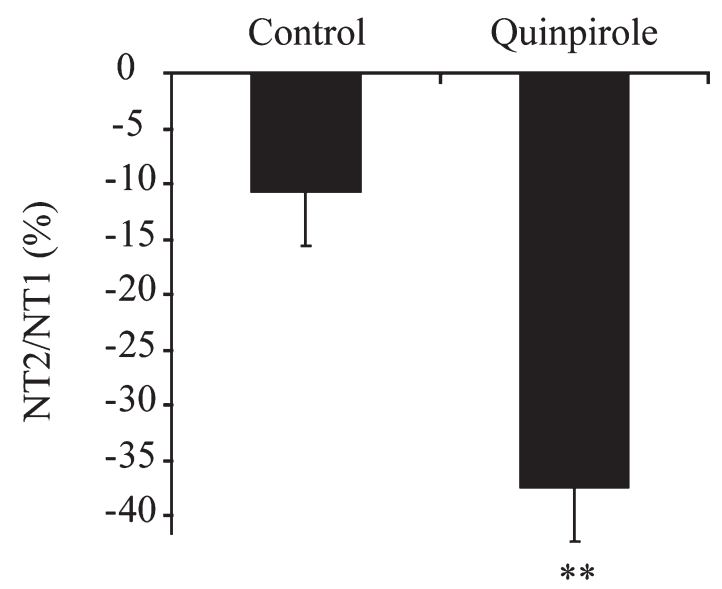

FIG. 6. D2R inhibits the ability of NTS1 to increase intracellular calcium in DA neurons. (A) Ratio images from a representative fura-2 $\mathrm{Ca}^{2+}{ }^{i m a g i n g}$ experiment. $\mathrm{DA}$ neurons were identified prior to the experiment by EGFP epifluorescence (not shown). (B and $\mathrm{C}$ ) Graphs showing the variation in intracellular Ca ${ }^{2+}$ concentration as a function of time in representative experiments. Neurotensin (NT(8-13)) (10 nM) was applied twice for 2 min, separated by a 25 -min washout period. On the second occasion, it was applied either alone (B) or in the presence of quinpirole (1 $\mu \mathrm{M})(\mathrm{C})$. (D) Summary graph showing the amplitude of the second response to NT relative to the first. The second application of NT was preceded by saline in control experiments (control $n=17)$ or by quinpirole $(n=18)$. Data are expressed as mean \pm SEM. $* * P<0.01$.

\section{Discussion}

Several lines of evidence suggest a close association between DA and NT systems in the CNS. It has been demonstrated that in addition to its direct excitatory effects on the excitability of DA neurons, NT through its high-affinity receptor, also modulates D2 autoreceptor function (Shi \& Bunney, 1991; Rostene et al., 1997; Werkman et al., 2000).
However, the mechanism underlying this interaction is still elusive. The present work provides novel information on the mechanism by which NT induces functional inhibition of D2R function. Using electrophysiological recordings, we made three major observations. First, we showed that NT, through the activation of a NTS1-like receptor, is effectively able to reduce D2 autoreceptor function in 
cultured DA neurons and that this effect is independent of the direct excitatory effect of this peptide. Second, we found that the functional interaction between D2R and NTS1 receptors requires $\mathrm{Ca}^{2+}$ and PKC activation. Finally, we demonstrated that the cross-talk between NTS1 and $\mathrm{D} 2 \mathrm{R}$ is bidirectional.

Because midbrain DA neurons are excited by NT and inhibited by DA, it has been suggested that the interaction between D2R and NTS1 functions results from an opposite regulation of a similar potassium conductance (Farkas et al., 1997). In the present set of experiments, we did not directly measure the activity of ionic channels influencing the excitability of DA neurons. Nonetheless, our results allow us to discount this earlier hypothesis. We had previously shown that the excitatory effect of NT on cultured rat DA neurons is $\mathrm{Ca}^{2+}$-dependent and implicates $\mathrm{IP}_{3}$ receptors (St-Gelais et al., 2004). In the present work, we similarly demonstrated that the excitatory effect of NT on cultured DA neurons from TH-GFP mice is blocked by BAPTA, a $\mathrm{Ca}^{2+}$ chelator, and by heparin, an $\mathrm{IP}_{3}$ receptor antagonist. Moreover, we found that including BAPTA in the intrapipette solution effectively blocked the functional regulation of the D2R by NTS1, while heparin was without effect on this interaction. These results suggest on the one hand that an increase in intracellular $\mathrm{Ca}^{2+}$ is required for the interaction to occur, and on the other that the major source of this $\mathrm{Ca}^{2+}$ is the extracellular medium, a finding compatible with our previous report showing that NT elevates intracellular $\mathrm{Ca}^{2+}$ in DA neurons mainly by promoting $\mathrm{Ca}^{2+}$ influx, with only a minor contribution from intracellular $\mathrm{Ca}^{2+}$ stores (St-Gelais et al., 2004). As it was possible to block the excitatory effect of NT without blocking the receptor interaction, we therefore conclude that the two mechanisms are independent. This conclusion is further supported by the previous demonstrations that NT is able to reduce the inhibitory effect of D2R agonists, even at concentrations of NT that do not increase firing by themselves (Shi \& Bunney, 1990, 1992; Nalivaiko et al., 1998; Werkman et al., 2000). Also in agreement with this conclusion, we found that although the excitatory effect of NT on firing was quite variable, the peptide always caused a robust inhibition of $\mathrm{D} 2 \mathrm{R}$ function, thus arguing in favour of independent mechanisms.

The functional interaction between D2R and NTS1 leads to a reduction of D2 autoreceptor function. We have not in the present work demonstrated direct receptor or signalling interactions between D2R and NTS1. The cross-talk between these two receptor systems could indeed involve a number of intermediate steps. However, the functional interaction we have described can nonetheless be considered a form of functional desensitization and could be caused by a loss of receptors from the cell surface, an uncoupling of receptors from their signal transduction pathways, or an alteration of distal components of these pathways. Our results with heparin argue against the possibility of an opposite regulation of a common effector. We thus favour the hypothesis that second-messenger pathways activated through NTS1 lead to a cascade of events promoting uncoupling of the D2 receptor from its signalling pathways. Because NTS1 is functionally coupled to the PLC, IP metabolism and PKC signalling cascades (Hermans \& Maloteaux, 1998; Vincent et al., 1999), and because PKC activation leads to phosphorylation and desensitization of many $\mathrm{Gi}$ and Gq-linked GPCRs (Haga et al., 1996; Oppermann et al., 1996; Diviani et al., 1997; Liang et al., 1998; Tang et al., 1998; Hipkin et al., 2000), we investigated the role of $\mathrm{PKC}$ in the $\mathrm{D} 2 \mathrm{R}-\mathrm{NTS} 1$ receptor interaction. We found that blocking PKC with the selective peptide inhibitor PKC(19-36) prevents the functional desensitization of $\mathrm{D} 2 \mathrm{R}$ induced by NTS1. The D2R possesses PKC phosphorylation sites within its third intracellular loop, a region that plays a central role in the coupling of GPCRs to their effectors. In addition, in heterologous cell lines, PKC can mediate phosphorylation of D2R to promote desensitization and internalization (Rogue et al., 1990; Namkung \& Sibley, 2004). Although additional data will be required to demonstrate this, it is therefore possible that the reduction in D2R function induced by NTS1 results from a direct phosphorylation of the D2R by PKC. However, the processes underlying heterologous desensitization are still not well understood, and it is likely that multiple mechanisms, in addition to phosphorylation of the D2R by $\mathrm{PKC}$, can contribute to this process. For example, it is possible that PKC acts through the phosphorylation of a GRK thus promoting homologous desensitization. Compatible with this possibility, it has been shown that GRK2, thought to be the major GRK involved in D2R internalization (Ito et al., 1999; Iwata et al., 1999; Kim et al., 2001), can be directly phosphorylated by PKC (Chuang et al., 1995) or that PKC increases its ability to interact with the receptor (Mundell et al., 2004), leading to an increase in its ability to promote desensitization (Chuang et al., 1996).

An alternate but not necessarily exclusive explanation of a D2RNTS1 interaction is that the two receptors physically interact. Indeed, an allosteric interaction between D2R and NTS1 has been previously proposed based on indirect data (Tanganelli et al., 1989; von Euler et al., 1991). It is now widely accepted that GPCRs form homo- and hetero-oligomers, the formation of which can influence their ligandbinding pharmacology, intracellular signal transduction and trafficking (Bouvier, 2001). Although the mechanistic details remain unclear, heteroreceptor-induced desensitization and internalization could result from direct protein-protein interactions. It has been previously shown that $\mathrm{D} 2 \mathrm{R}$ can form heterodimers with the adenosine A2A receptor (Fuxe et al., 1998; Hillion et al., 2002; Canals et al., 2003; Kamiya et al., 2003), as well as the somatostatin SSTR5 receptor (Rocheville et al., 2000) and, more recently, with the cannabinoid CB1 receptor (Kearn et al., 2005). Moreover, there is compelling evidence in heterologous cell lines that the heterodimerization between D2R and the $\mathrm{A} 2 \mathrm{~A}$ receptor is responsible for the heterologous desensitization of D2R following A2A receptor stimulation (Yang et al., 1995; Salim et al., 2000; Hillion et al., 2002). Although there is no evidence yet supporting a direct interaction between D2R and NTS1, we cannot presently exclude this possibility.

Finally, we demonstrated that the D2R can reduce the ability of NTS1 to induce $\mathrm{Ca}^{2+}$ mobilization in cultured DA neurons. Although a previous study has shown a similar phenomenon in rat pituitary cells (Memo et al., 1985), this is the first report of a bidirectional antagonistic interaction of D2 and NTS1 receptors. The mechanism of this reverse interaction is presently unexplored. The concept of bidirectional interactions between GPCRs is widespread, as highlighted by the recent observation of a similar relationship between $\mu$-opioid and chemokine receptors (Rogers et al., 2000), cannabinoid CB1 and $\delta$-opioid receptors (Shapira et al., 2003), and for angiotensin II and alpha 1 adrenergic receptors (Jerez et al., 2004).

The D2R acts as an autoreceptor and feedback regulator of DA neurons (Lacey et al., 1987; Chiodo \& Kapatos, 1992; Mercuri et al., 1997). It is otherwise known to exhibit relatively weak homologous desensitization (Sibley \& Neve, 1997). Its functional regulation by NT, through NTS1, could thus be a critical mechanism to regulate the activity of DA neurons. The consequences of the regulation of NTS1 receptor signalling by the D2R have been less explored. However, this action would act as an ideal feedback system to dampen any excessive activity of DA neurons as an accumulation of extracellular DA would not only directly activate the D2 autoreceptor and its associated potassium conductances, but it would at the same time lead to partial inhibition of an excitatory peptidergic system. 


\section{Acknowledgements}

This work was supported by a grant from the Canadian Institutes of Health Research to L.-E.T. L.-E.T. is a senior scholar of the Fonds de la Recherche en Santé du Québec (FRSQ). C.J. was supported by a graduate studentship from the FRSQ. We thank Julie Robillard for her contribution to preliminary experiments that helped to initiate this study.

\section{Abbreviations}

DA, dopamine; EGFP, enhanced green fluorescent protein; IP, inositol phosphate; NT, neurotensin; PCR, polymerase chain reaction; PKC, protein kinase C; PLC, phospholipase C; SN, substantia nigra; TH, tyrosine hydroxylase; VTA, ventral tegmental area.

\section{References}

Binder, E.B., Kinkead, B., Owens, M.J. \& Nemeroff, C.B. (2001) Neurotensin and dopamine interactions. Pharmacol. Rev., 53, 453-486.

Borges, S., Gleason, E., Frerking, M. \& Wilson, M. (1996) Neurotensin induces calcium oscillations in cultured amacrine cells. Vis. Neurosci., 13, 311-318.

Bouvier, M. (2001) Oligomerization of G-protein-coupled transmitter receptors. Nat. Rev. Neurosci., 2, 274-286.

Brouard, A., Pelaprat, D., Dana, C., Vial, M., Lhiaubet, A.M. \& Rostene, W. (1992) Mesencephalic dopaminergic neurons in primary cultures express functional neurotensin receptors. J. Neurosci., 12, 1409-1415.

Canals, M., Marcellino, D., Fanelli, F., Ciruela, F., de Benedetti, P., Goldberg, S.R., Neve, K., Fuxe, K., Agnati, L.F., Woods, A.S., Ferre, S., Lluis, C., Bouvier, M. \& Franco, R. (2003) Adenosine A2A-dopamine D2 receptorreceptor heteromerization: qualitative and quantitative assessment by fluorescence and bioluminescence energy transfer. J. Biol. Chem., 278, 46741-46749.

Chiodo, L.A. \& Kapatos, G. (1992) Membrane properties of identified mesencephalic dopamine neurons in primary dissociated cell culture. Synapse, 11, 294-309.

Chuang, T.T., Iacovelli, L., Sallese, M. \& De Blasi, A. (1996) G proteincoupled receptors: heterologous regulation of homologous desensitization and its implications. Trends Pharmacol. Sci., 17, 416-421.

Chuang, T.T., LeVine, H. 3rd \& De Blasi, A. (1995) Phosphorylation and activation of beta-adrenergic receptor kinase by protein kinase C. J. Biol. Chem., 270, 18660-18665.

Delle Donne, K.T., Chan, J., Boudin, H., Pelaprat, D., Rostene, W. \& Pickel, V.M. (2004) Electron microscopic dual labeling of high-affinity neurotensin and dopamine D2 receptors in the rat nucleus accumbens shell. Synapse, 52, 176-187.

Diviani, D., Lattion, A.L. \& Cotecchia, S. (1997) Characterization of the phosphorylation sites involved in $\mathrm{G}$ protein-coupled receptor kinase- and protein kinase $\mathrm{C}$-mediated desensitization of the alpha1B-adrenergic receptor. J. Biol. Chem., 272, 28712-28719.

von Euler, G., Fuxe, K., Benfenati, F., Hansson, T., Agnati, L.F. \& Gustafsson, J.A. (1989) Neurotensin modulates the binding characteristics of dopamine D2 receptors in rat striatal membranes also following treatment with toluene. Acta Physiol. Scand., 135, 443-448.

von Euler, G., van der Ploeg, I., Fredholm, B.B. \& Fuxe, K. (1991) Neurotensin decreases the affinity of dopamine D2 agonist binding by a G proteinindependent mechanism. J. Neurochem., 56, 178-183.

Farkas, R.H., Chien, P.Y., Nakajima, S. \& Nakajima, Y. (1996) Properties of a slow nonselective cation conductance modulated by neurotensin and other neurotransmitters in midbrain dopaminergic neurons. J. Neurophysiol., 76, 1968-1981.

Farkas, R.H., Chien, P.Y., Nakajima, S. \& Nakajima, Y. (1997) Neurotensin and dopamine D2 activation oppositely regulate the same $\mathrm{K}+$ conductance in rat midbrain dopaminergic neurons. Neurosci. Lett., 231, 21-24.

Fassio, A., Evans, G., Grisshammer, R., Bolam, J.P., Mimmack, M. \& Emson, P.C. (2000) Distribution of the neurotensin receptor NTS1 in the rat CNS studied using an amino-terminal directed antibody. Neuropharmacology, 39, $1430-1442$.

Fuxe, K., Ferre, S., Zoli, M. \& Agnati, L.F. (1998) Integrated events in central dopamine transmission as analyzed at multiple levels. Evidence for intramembrane adenosine A2A/dopamine D2 and adenosine A1/dopamine D1 receptor interactions in the basal ganglia. Brain Res. Brain Res. Rev., 26, 258-273.
Fuxe, K., Von Euler, G., Agnati, L.F., Merlo Pich, E., O'Connor, W.T., Tanganelli, S., Li, X.M., Tinner, B., Cintra, A., Carani, C. \& Benfenati, F. (1992) Intramembrane interactions between neurotensin receptors and dopamine D2 receptors as a major mechanism for the neuroleptic-like action of neurotensin. Ann. N Y Acad. Sci., 668, 186-204.

Grynkiewicz, G., Poenie, M. \& Tsien, R.Y. (1985) A new generation of Ca2+ indicators with greatly improved fluorescence properties. J. Biol. Chem., 260, 3440-3450.

Haga, K., Kameyama, K., Haga, T., Kikkawa, U., Shiozaki, K. \& Uchiyama, H. (1996) Phosphorylation of human $\mathrm{m} 1$ muscarinic acetylcholine receptors by $\mathrm{G}$ protein-coupled receptor kinase 2 and protein kinase C. J. Biol. Chem., 271, 2776-2782.

Hermans, E. \& Maloteaux, J.M. (1998) Mechanisms of regulation of neurotensin receptors. Pharmacol. Ther, 79, 89-104.

Hillion, J., Canals, M., Torvinen, M., Casado, V., Scott, R., Terasmaa, A., Hansson, A., Watson, S., Olah, M.E., Mallol, J., Canela, E.I., Zoli, M., Agnati, L.F., Ibanez, C.F., Lluis, C., Franco, R., Ferre, S. \& Fuxe, K. (2002) Coaggregation, cointernalization, and codesensitization of adenosine A2A receptors and dopamine D2 receptors. J. Biol. Chem., 277, 18091-18097.

Hipkin, R.W., Wang, Y. \& Schonbrunn, A. (2000) Protein kinase C activation stimulates the phosphorylation and internalization of the sst2A somatostatin receptor. J. Biol. Chem., 275, 5591-5599.

Ito, K., Haga, T., Lameh, J. \& Sadee, W. (1999) Sequestration of dopamine D2 receptors depends on coexpression of G-protein-coupled receptor kinases 2 or 5. Eur. J. Biochem., 260, 112-119.

Iwata, K., Ito, K., Fukuzaki, A., Inaki, K. \& Haga, T. (1999) Dynamin and rab5 regulate GRK2-dependent internalization of dopamine D2 receptors. Eur. J. Biochem., 263, 596-602.

Jennes, L., Stumpf, W.E. \& Kalivas, P.W. (1982) Neurotensin: topographical distribution in rat brain by immunohistochemistry. J. Comp. Neurol., 210, 211-224.

Jerez, S., Peral de Bruno, M. \& Coviello, A. (2004) Cross talk between angiotensin II and alpha 1 adrenergic receptors in rabbit aorta: role of endothelium. J. Cardiovasc. Pharmacol., 43, 402-409.

Jiang, Z.G., Pessia, M. \& North, R.A. (1994) Neurotensin excitation of rat ventral tegmental neurones. J. Physiol., 474, 119-129.

Jomphe, C., Bourque, M.J., Fortin, G.D., St-Gelais, F., Okano, H., Kobayashi, K. \& Trudeau, L.E. (2005) Use of TH-EGFP transgenic mice as a source of identified dopaminergic neurons for physiological studies in postnatal cell culture. J. Neurosci. Meth., 146, 1-12.

Kamiya, T., Saitoh, O., Yoshioka, K. \& Nakata, H. (2003) Oligomerization of adenosine A2A and dopamine D2 receptors in living cells. Biochem. Biophys. Res. Commun., 306, 544-549.

Kearn, C.S., Blake-Palmer, K., Daniel, E., Mackie, K. \& Glass, M. (2005) Concurrent stimulation of cannabinoid CB1 and dopamine D2 receptors enhances heterodimer formation: a mechanism for receptor cross-talk? Mol. Pharmacol., 67, 1697-1704.

Kim, K.M., Valenzano, K.J., Robinson, S.R., Yao, W.D., Barak, L.S. \& Caron, M.G. (2001) Differential regulation of the dopamine D2 and D3 receptors by $\mathrm{G}$ protein-coupled receptor kinases and beta-arrestins. J. Biol. Chem., 276, 37409-37414.

Lacey, M.G., Mercuri, N.B. \& North, R.A. (1987) Dopamine acts on D2 receptors to increase potassium conductance in neurones of the rat substantia nigra zona compacta. J. Physiol., 392, 397-416.

Li, X.M., Ferraro, L., Tanganelli, S., O'Connor, W.T., Hasselrot, U., Ungerstedt, U. \& Fuxe, K. (1995) Neurotensin peptides antagonistically regulate postsynaptic dopamine D2 receptors in rat nucleus accumbens: a receptor binding and microdialysis study. J. Neural Transm. Gen. Sect., 102, 125-137.

Liang, M., Eason, M.G., Jewell-Motz, E.A., Williams, M.A., Theiss, C.T., Dorn, G.W. 2nd \& Liggett, S.B. (1998) Phosphorylation and functional desensitization of the alpha2A-adrenergic receptor by protein kinase C. Mol. Pharmacol., 54, 44-49.

Matsushita, N., Okada, H., Yasoshima, Y., Takahashi, K., Kiuchi, K. \& Kobayashi, K. (2002) Dynamics of tyrosine hydroxylase promoter activity during midbrain dopaminergic neuron development. J. Neurochem., 82, 295-304.

Memorandum, M., Carboni, E., Trabucchi, M., Carruba, M.O. \& Spano, P.F. (1985) Dopamine inhibition of neurotensin-induced increase in Ca2+ influx into rat pituitary cells. Brain Res., 347, 253-257.

Mercuri, N.B., Saiardi, A., Bonci, A., Picetti, R., Calabresi, P., Bernardi, G. \& Borrelli, E. (1997) Loss of autoreceptor function in dopaminergic neurons from dopamine D2 receptor deficient mice. Neuroscience, 79, 323-327.

Mercuri, N.B., Stratta, F., Calabresi, P. \& Bernardi, G. (1993) Neurotensin induces an inward current in rat mesencephalic dopaminergic neurons. Neurosci. Lett., 153, 192-196. 
Moyse, E., Rostene, W., Vial, M., Leonard, K., Mazella, J., Kitabgi, P., Vincent, J.P. \& Beaudet, A. (1987) Distribution of neurotensin binding sites in rat brain: a light microscopic radioautographic study using monoiodo. Neuroscience, 22, 525-536.

Mundell, S.J., Pula, G., McIlhinney, R.A., Roberts, P.J. \& Kelly, E. (2004) Desensitization and internalization of metabotropic glutamate receptor 1a following activation of heterologous $\mathrm{Gq} / 11$-coupled receptors. Biochemistry, 43, 7541-7551.

Nalivaiko, E., Michaud, J.C., Soubrie, P. \& Le Fur, G. (1998) Electrophysiological evidence for putative subtypes of neurotensin receptors in guinea-pig mesencephalic dopaminergic neurons. Neuroscience, 86, 799-811.

Namkung, Y. \& Sibley, D.R. (2004) Protein kinase C mediates phosphorylation, desensitization, and trafficking of the D2 dopamine receptor. J. Biol. Chem., 279, 49533-49541.

Nicot, A., Rostene, W. \& Berod, A. (1995) Differential expression of neurotensin receptor mRNA in the dopaminergic cell groups of the rat diencephalon and mesencephalon. J. Neurosci. Res., 40, 667-674.

Oppermann, M., Freedman, N.J., Alexander, R.W. \& Lefkowitz, R.J. (1996) Phosphorylation of the type 1A angiotensin II receptor by $\mathrm{G}$ protein-coupled receptor kinases and protein kinase C. J. Biol. Chem., 271, 13266-13272.

Palacios, J.M. \& Kuhar, M.J. (1981) Neurotensin receptors are located on dopamine-containing neurones in rat midbrain. Nature, 294, 587-589.

Pinnock, R.D. (1985) Neurotensin depolarizes substantia nigra dopamine neurones. Brain Res., 338, 151-154.

Quirion, R. (1983) Interactions between neurotensin and dopamine in the brain: an overview. Peptides, 4, 609-615.

Quirion, R., Chiueh, C.C., Everist, H.D. \& Pert, A. (1985) Comparative localization of neurotensin receptors on nigrostriatal and mesolimbic dopaminergic terminals. Brain Res., 327, 385-389.

Rocheville, M., Lange, D.C., Kumar, U., Patel, S.C., Patel, R.C. \& Patel, Y.C. (2000) Receptors for dopamine and somatostatin: formation of heterooligomers with enhanced functional activity. Science, 288, 154-157.

Rogers, T.J., Steele, A.D., Howard, O.M. \& Oppenheim, J.J. (2000) Bidirectional heterologous desensitization of opioid and chemokine receptors. Ann. N Y Acad. Sci., 917, 19-28.

Rogue, P., Zwiller, J., Malviya, A.N. \& Vincendon, G. (1990) Phosphorylation by protein kinase $\mathrm{C}$ modulates agonist binding to striatal dopamine D2 receptors. Biochem. Int., 22, 575-582.

Rostene, W., Azzi, M., Boudin, H., Lepee, I., Souaze, F., Mendez-Ubach, M., Betancur, C. \& Gully, D. (1997) Use of nonpeptide antagonists to explore the physiological roles of neurotensin. Focus on brain neurotensin/dopamine interactions. Ann. N Y Acad. Sci., 814, 125-141.

Salim, H., Ferre, S., Dalal, A., Peterfreund, R.A., Fuxe, K., Vincent, J.D. \& Lledo, P.M. (2000) Activation of adenosine A1 and A2A receptors modulates dopamine D2 receptor-induced responses in stably transfected human neuroblastoma cells. J. Neurochem., 74, 432-439.

Sawamoto, K., Nakao, N., Kobayashi, K., Matsushita, N., Takahashi, H., Kakishita, K., Yamamoto, A., Yoshizaki, T., Terashima, T., Murakami, F., Itakura, T. \& Okano, H. (2001) Visualization, direct isolation, and transplantation of midbrain dopaminergic neurons. Proc. Natl Acad. Sci. USA, 98, 6423-6428.
Seutin, V., Massotte, L. \& Dresse, A. (1989) Electrophysiological effects of neurotensin on dopaminergic neurones of the ventral tegmental area of the rat in vitro. Neuropharmacology, 28, 949-954.

Shapira, M., Gafni, M. \& Sarne, Y. (2003) Long-term interactions between opioid and cannabinoid agonists at the cellular level: cross-desensitization and downregulation. Brain Res., 960, 190-200.

Shi, W.S. \& Bunney, B.S. (1990) Neurotensin attenuates dopamine D2 agonis quinpirole-induced inhibition of midbrain dopamine neurons. Neuropharmacology, 29, 1095-1097.

Shi, W.X. \& Bunney, B.S. (1991) Neurotensin modulates autoreceptor mediated dopamine effects on midbrain dopamine cell activity. Brain Res., 543, 315-321.

Shi, W.X. \& Bunney, B.S. (1992) Actions of neurotensin: a review of the electrophysiological studies. Ann. N Y Acad. Sci., 668, 129-145.

Sibley, D.R. \& Neve, K.A. (1997) Regulation of dopamine receptor function and expression. In Neve, K.A. \& Neve, R.L. (Eds), The Dopamine Receptors. Humana Press, Totowa, New Jersey, USA, pp. 383-424.

St-Gelais, F., Legault, M., Bourque, M.J., Rompre, P.P. \& Trudeau, L.E. (2004) Role of calcium in neurotensin-evoked enhancement in firing in mesencephalic dopamine neurons. J. Neurosci., 24, 2566-2574.

Tang, H., Guo, D.F., Porter, J.P., Wanaka, Y. \& Inagami, T. (1998) Role of cytoplasmic tail of the type $1 \mathrm{~A}$ angiotensin II receptor in agonist- and phorbol ester-induced desensitization. Circ. Res., 82, 523-531.

Tanganelli, S., Li, X.M., Ferraro, L., Von Euler, G., O’Connor, W.T., Bianchi, C., Beani, L. \& Fuxe, K. (1993) Neurotensin and cholecystokinin octapeptide control synergistically dopamine release and dopamine D2 receptor affinity in rat neostriatum. Eur. J. Pharmacol., 230, 159-166.

Tanganelli, S., von Euler, G., Fuxe, K., Agnati, L.F. \& Ungerstedt, U. (1989) Neurotensin counteracts apomorphine-induced inhibition of dopamine release as studied by microdialysis in rat neostriatum. Brain Res., 502 , 319-324.

Uhl, G.R. (1982) Distribution of neurotensin and its receptor in the central nervous system. Ann. N Y Acad. Sci., 400, 132-149.

Uhl, G.R., Kuhar, M.J. \& Snyder, S.H. (1977) Neurotensin: immunohistochemical localization in rat central nervous system. Proc. Natl Acad. Sci. USA, 74, 4059-4063.

Vincent, J.P., Mazella, J. \& Kitabgi, P. (1999) Neurotensin and neurotensin receptors. Trends Pharmacol. Sci., 20, 302-309.

Werkman, T.R., Kruse, C.G., Nievelstein, H., Long, S.K. \& Wadman, W.J. (2000) Neurotensin attenuates the quinpirole-induced inhibition of the firing rate of dopamine neurons in the rat substantia nigra pars compacta and the ventral tegmental area. Neuroscience, 95, 417-423.

Yang, S.N., Dasgupta, S., Lledo, P.M., Vincent, J.D. \& Fuxe, K. (1995) Reduction of dopamine D2 receptor transduction by activation of adenosine A2a receptors in stably A2a/D2 (long-form) receptor co-transfected mouse fibroblast cell lines: studies on intracellular calcium levels. Neuroscience, $\mathbf{6 8}$, 729-736.

Zahm, D.S., Grosu, S., Williams, E.A., Qin, S. \& Berod, A. (2001) Neurons of origin of the neurotensinergic plexus enmeshing the ventral tegmental area in rat: retrograde labeling and in situ hybridization combined. Neuroscience, 104, 841-851. 